Submitted on January 25, 2019.

\title{
Composition, stability and stereo effects of zirconium(IV) $d l$-tartrate formation
}

\author{
(C) Lilia I. Mukhamedyarova, ${ }^{1}$ Sergey G. Bezryadin, ${ }^{2}{ }^{+}$Vladimir V. Chevela, ${ }^{3}$ \\ Valentina Yu. Ivanova, ${ }^{3}$ and Elena Yu. Klukvina ${ }^{2}$ \\ ${ }^{1}$ Chemistry and Chemistry Teaching Methodology Department. Orenburg State Pedagogical University. \\ Sovetskaya St., 19. Orenburg, 460014. Orenburg Region. Russia. Phone: +7 (3532) 77-70-85. \\ ${ }^{2}$ Chemical Technology of Oil Refining, Gas and Ecology Department. Gubkin Russian State University of Oil \\ and Gas (National Research University). Orenburg Branch. Yunykh Lenintsev St., 20. Orenburg, 460047. \\ Orenburg Region. Russia.Phone: +7 (3532) 62-94-21.E-mail: sergbezryadin@mail.ru \\ ${ }^{3}$ Inorganic Chemistry Department. Alexander Butlerov Chemistry Institute. Kazan (Volga region) Federal \\ University. Kremlyovskaya St., 18. Kazan, 420008. Republic of Tatarstan. Russia. Phone: +7 (843) 231-54-16.
}

*Supervising author; ${ }^{+}$Corresponding author

Keywords: zirconium(IV) tartrates, complexation, potentiometric titration, mathematical modeling.

\section{Abstract}

The system of zirconium(IV) - $d l$-tartaric acid for metal: ligand 1: 1, 1:2 and 1:3 ratios in aqueous solution has been studied by means of using potentiometric titration method in combination with mathematical modeling. The comparison of Bjerrum functions from $\mathrm{pH}$ for zirconium(IV) systems: $d$-tartaric acid and zirconium(IV): $d l$-tartaric acid, has revealed the following features in the behavior of the curves: the degree of titration for the complexes at a fixed $\mathrm{pH}$ value for systems with $d l$-tartaric acid is more than for $d$ acid. The CPESSP software complex has calculated the composition, stability constants and molar fractions of zirconium(IV) tartrate accumulation. It has been also found that at a ratio of 1: 1 for $\mathrm{Zr}(\mathrm{IV})$ and ligand $\left(\mathrm{H}_{4}\right.$ Tart) ions in the system under study ZrHTart ${ }^{+}$is formed, which is tetramerized into $\mathrm{Zr}_{4} \mathrm{Tart}_{4}{ }^{0}$ and, further, tetranuclear particles of varying degrees of deprotonization are formed, as well as mononuclear forms. In a strongly alkaline $\mathrm{pH}$ environment $>10$, Bjerrum curves for $d$ - and $d l$-tartaric acids overlap each other and correspond to hydroxocomplexes of varying degrees of titration. For the 1:2 ratio, the composition of the complexes for the zirconium(IV) $-d l-\mathrm{H}_{4} \mathrm{~T}$ system is slightly different; compared to the zirconium(IV) $-\mathrm{dH}_{4} \mathrm{~T}$ system, differences are clearly observed for both low and high concentrations. Based on these data, a complex formation scheme in the $\mathrm{Zr}(\mathrm{IV})$ - $d l$-tartaric acid system has been proposed for all the ratios studied. The characteristics of stereoselective diastereomer formation have been calculated. It has been revealed that in the medium of racemic tartrate, $d d d$ - and $l l l-\mathrm{Zr}\left(\mathrm{H}_{2} \text { Tart }\right)_{2}(\mathrm{HTart})^{3-}$ forms, as well as $\mathrm{Zr}\left(\mathrm{H}_{2}\right.$ Tart $)(\mathrm{HTart})_{2}{ }^{4-} \mathrm{Zr}(\mathrm{HT} \text { art })_{3}{ }^{5-}$ are formed on a stereoselective basis.

\section{References}

[1] L.A. Tomachinskaya, V.Ya. Cherny, E.N. Gorbenko, V.V. Filonenko, S.V. Volkov. Cytotoxic antitumor activity of a new mixed ligand phthalocyanine complex of zirconium with lysine. Ukrainian chemical journal. 2003. Vol.69. No.3-4. P.11-12.

[2] V.V. Kozik, L.N. Borilo, E.B. Chernov, E.A. Lyskova. Thin-film nanosystems based on double oxides of zirconium and germanium. News of Tomsk Polytechnic University. 2006. Vol.309. No.5. P.64-68. (russian)

[3] L.N. Borilo, V.V. Kozik. Obtaining and studying the properties of thin films based on double oxides $\mathrm{ZrO}_{2}-\mathrm{GeO}_{2}$. Proceedings of higher educational institutions. Chemistry and chemical technology. 2006. Vol.49. No.9. P.106-109. (russian)

[4] K.V. Zherikova, N.B. Morozova, N.V. Kuratyeva, I.A. Baydina and others. X-ray study of fluorinated $\beta$ diketonate complexes of zirconium(IV). Journal of structural chemistry. 2007. Vol.48. No.3. P.555-563. (russian)

[5] Z.M. Dzhabiyeva, G.V. Shilov, T.S. Jabiyev. Synthesis, structure and catalytic properties of the complex of tetravalent zirconium with trifluoroacetal acetone. Coordination chemistry. 2008. Vol.34. No.7. P.546550. (russian) 
[6] M.V. Burova, A.V. Fionov, E.A. Tveritinova, A.N. Kharlanov, V.V. Lunin. The electron acceptor and catalytic properties of zirconium dioxide modified with aluminum and gallium oxides. Russian Journal of Physical Chemistry. 2007. Vol.81. No.2. P.164-169.

[7] L.Yu. Buldakova, V.G. Kharchuk, A.B. Shishmakov, O.V. Kuznetsova, O.V. Koryakova, L.A. Petrovidr. Study of the structure and properties of promising catalysts $-\mathrm{Cu}(\mathrm{II})$ complexes with zirconium hydrogels. Volga conference on analytical chemistry. Abstracts. Kazan, November 20-22. 2001. P.52. (russian)

[8] R.A. Sadykov, P.N. Petrov, M.G. Shaibakova, U.M. Dzhemilev. Chemically induced dynamic polarization of nuclei in the dehalogenation of hem-dihalocyclopropanes under the action of $\mathrm{i}-\mathrm{Bu}_{2} \mathrm{AlH}$ in the presence of $\mathrm{Zr}$ (acac) $)_{4}$. Kinetics and catalysis. 2007. Vol.48. No.5. P.701-705. (russian)

[9] I.V. Pyatnitsky. Sukhan. Masking and unmasking in analytical chemistry. Moscow: Science. 1990. 222p. (russian)

[10] I.V. Pyatnitsky, L.M. Glushchenko, Ye.A. Pogrebnaya. Research and analytical application of the tartrate - cobalt - aluminum complexes (zirconium, bismuth). Journal of Analytical Chemistry. 1974. Vol.29. No.8. P.1599-1602. (russian)

[11] V.A. Nazarenko, V.P. Antonovich, E.M. Nevskaya. Hydrolysis of metal ions in dilute solutions. Moscow: Atomizdat. 1979. 192p. (russian)

[12] A. Singhal, L. Toht, J. Lin, K. Affholter. Zirconium(IV) tetramer/octamer hydrolysis equilibrium in aqueous hydrochloric acid solution. Journal of American Chemical Society. 1996. Vol.118. No.3. P.11529-11534.

[13] C. Walther, J. Rothe, M. Fuss, S. Büchner, S. Koltsov, T. Bergmann. Investigation of polynuclearZr (IV) hydroxide complexes by nanoelectrospray mass-spectrometry combined with XAFS. Analytical and bioanalytical chemistry. 2007. Vol.388. No.2. P.409-431.

[14] E. Mentasti, C. Baiocchi. The equilibria and kinetics of the complex formation between Fe(III) and tartaric and citric acids. Journal of Coordination Chemistry. 1980. Vol.10. No.4. P.229-237.

[15] S.G. Bezryadin, V.V. Chevela, O.P. Ajsuvakova, and V.Yu. Ivanova. Titanium(IV) citrates in aqueouschloride solutions. Butlerov Communications. 2013. Vol.35. No.8. P.59-66. ROI: jbc-02/13-35-8-59

[16] V.V. Kanazhevsky, V.P. Shmachkova, N.S. Kotsarenko, V.N. Kolomiychuk, D.I. Kochubey. Changes in the local environment of zirconium when replacing ligands in solutions. Journal of structural chemistry. 2006. Vol.47. No.5. P.874-881. (russian)

[17] S.G. Bezryadin, V.V. Chevela, O.P. Aysuvakova, V.Yu. Ivanova, D.V. Kuzyakin. Tartrate complexes of titanium (IV) in aqueous solutions. News of the Academy of Sciences. Chemical series. 2015. No.11. P.2655. (russian)

[18] L.I. Muhamedyarova, S.G. Bezryadin, V.V. Chevela, N.A. Grigorieva, V.S. Zalymov, V.Yu. Ivanova. Composition, stability and structure of zirconium(IV) citrates in aqueous solutions. Bulletin of the Orenburg State University. 2010. No.12-1(118). P.22-26. (russian)

[19] G. Charlo. Methods of analytical chemistry. Moscow: Mir. 1965. 950p. (russian)

[20] Yu.I. Salnikov, A.N. Glebov, F.V. Devyatov. Polynuclear complexes in solutions. Kazan: Publishing House of KSU. 1989. 287p. (russian)

[21] L.I. Mukhamedyarova, S.G. Bezryadin, V.V. Chevela. Complexation of zirconium(IV) in aqueous solutions of tartaric acid. Structure and Dynamics of Molecular Systems: Sat: Abstracts of Reports and Messages XXI Vses. conf. Ufa: IFMK UC RAS. 2014. 163p. (russian)

[22] L.I. Mukhamedyarova, S.G. Bezryadin, V.V. Chevela, L.K. Lushnikova. Composition, stability and structure of zirconium(IV) $d$-tartrates in aqueous solutions. Prospects for the development of science and education. Collection of scientific papers on the materials of the International Scientific and Practical Conference: in V parts. AR-Consult Limited Liability Company. Moscow. 2014. P.40-41. (russian) 